\title{
Derivas de la izquierda peronista a través de las lecturas de 18 de marzo y Compañero
}

\section{Drifts of the Peronist left through the readings of 18 de marzo y Compañero}

\author{
Valeria Caruso \\ Instituto de Historia Argentina y Americana "Dr. Emilio Ravignani” \\ Universidad de Buenos Aires \\ Consejo Nacional de Investigaciones Científicas y Técnicas \\ caruso.valeria@gmail.com
}

(Argentina)

\section{Resumen}

Este artículo analiza los semanarios 18 de marzo (1962-1963) y Compañero (1963-1965) dirigidos por Mario Valotta. En estas publicaciones se advierten disputas por la identidad peronista a comienzos de la década del 60, y la progresiva configuración de discursos, marcas de autoridad, y proyecciones políticas que delinearon los contornos de la izquierda peronista como cultura política. Se examinan los modos situados de poner en escena y de buscar instalar públicamente formas de ser y estar en el peronismo en el contexto de reorganización partidaria demandado por Perón luego de las elecciones presidenciales de julio de 1963.

Palabras Clave: Compañero, 18 de marzo, Izquierda Peronista, Peronismo.

\begin{abstract}
This article analyzes the weeklies 18 de Marzo (1962-1963) and Compañero (1963-1965) directed by Mario Valotta. In these, we can notice several disputes over the Peronist identity in the early 1960s, and the onward configuration of speeches, authority marks, and political projections that outlined the Peronist left as a political culture. The ways of staging and publicly install a particular way to be in Peronism in the context of party reorganization demanded by Perón after the presidential elections of July 1963 are examined.
\end{abstract}

Keywords: Compañero, 18 de marzo, Peronist Left, Peronism. 


\section{Introducción}

$\mathrm{El}$ análisis de publicaciones periódicas ha permitido recorrer las tramas políticas e intelectuales que se articularon a partir de la crisis política que desató en la Argentina el Golpe de Estado de septiembre de 1955. Las prohibiciones impuestas por la autoproclamada Revolución Libertadora al peronismo, ampliadas posteriormente a otras fuerzas políticas, junto con la influencia de los procesos de liberación nacional que se dieron en el mundo entre fines de la década del '50 y principios de los '60, signó de manera profunda a aquellas fuerzas políticas que se propusieron transformar el orden de cosas vigentes.

Varias de estas cuestiones fueron observadas en distintas investigaciones destinadas a analizar la prensa política del periodo. Esos trabajos permitieron advertir tanto la emergencia de diversos nucleamientos políticos provenientes de tradiciones partidarias diversas, como procesos de reconfiguración ideológica e identitaria que se vivenciaron por entonces. ${ }^{1}$

En esa línea puede inscribirse el análisis de los semanarios 18 de marzo y Compañero, ambos dirigidos por Mario Valotta. ${ }^{2}$ Si bien el trabajo de Marcelo Raimundo (2000) sobre esta última publicación fue pionero al advertir en sus páginas la emergencia en la escena pública de conceptos propios de la izquierda peronista (en adelante, IP), su examen se ha centrado en

1. Véase: Melon Pirro (2007), Tortti (2010, 2014).

2. Valotta comenzó su militancia política en las filas del ala izquierda del Movimiento Universitario Reformista. Fue asesor privado del gobierno del Dr. Arturo Frondizi, hasta mediados de 1958. A partir de entonces, desde la dirección del periódico Democracia impulsó un movimiento de acercamiento hacia el peronismo, que se pronunciaría en las publicaciones que son objeto de análisis de este trabajo.

42 el proceso formativo del Movimiento Revolucionario Peronista (en adelante, MRP), organización que ha sido considerada como uno de los mojones del Peronismo Revolucionario, y antecedente directo de las Juventud Revolucionaria Peronista (en adelante, JRP) y las Fuerzas Armadas Peronistas (Bozza, 2001).

No obstante, el examen de 18 de marzo y de los primeros números de Compañero -sobre todo durante el periodo previo a la aparición del MRP en agosto de 1964-, pone de manifiesto distintas discusiones acerca de los rumbos que el peronismo proscripto debía adoptar, que difícilmente pueden reducirse al surgimiento del MRP. ${ }^{3}$ Más aún, en esas discusiones se encuentran elementos que permiten realizar una aproximación al proceso de articulación de la izquierda peronista como cultura política. ${ }^{4}$

Al hablar de cultura política, se refiere a una red de significados que da sentido a la percepción de los actores que en ella confluyen ante una realidad situada, y que es significada por éstos en función de los valores y de las prácticas con las que intentan intervenir en la esfera de las actividades políticas. Una de las hipótesis que guía esta indagación plantea que en estos semanarios se desplegaron discursos y posicio-

3. El semanario 18 de marzo, tuvo nueve números entre diciembre de 1962 y febrero de 1963. La primera época de Compañero estuvo compuesta por 79 números, entre el 7 de junio de 1963 y la primera quincena de abril de 1965. Este trabajo se centra en el período inicial de esta publicación, es decir, hasta la conformación del MRP en agosto de 1964.

4. Hemos explorado la categoría de izquierda peronista siguiendo la propuesta de Rodney Needham (1975) como clasificador "politético", el cual permite situar históricamente las distintas reapropiaciones creativas realizadas por diversos actores respecto de los componentes que integraron el universo significante del ala izquierda del peronismo (Caruso, Campos, Vigo y Acha, 2017). 
namientos que incidieron en la configuración de una identidad política, funcionando como uno de los escenarios en los que esas luchas identitarias hacia el interior del peronismo se tramaron y plasmaron a través del despliegue de distintas estrategias de legitimación. ${ }^{5}$

En los siguientes apartados se revisarán los modos situados de poner en escena y de instalar públicamente formas de "peronicidad" que habilitaron, al mismo tiempo que, intentaron reconfigurar modos de ser y estar en el peronismo para un sector del heterogéneo movimiento. Por peronicidad se entiende aquí a las maneras situadas en las que los actores desplegaron enunciados para probar su condición de peronistas. Lo cual requería que estos fueran "interpretables, comprensibles, inteligibles para otros actores dedicados ellos también a producir de manera exitosa su condición de peronistas" (Garzón Rogé, 2017, p. 3). En ese sentido, este trabajo examina cómo se fue construyendo una peronicidad particular en un contexto político marcado no solo por las prohibiciones vigentes para el peronismo, sino también, por las disputas internas que atravesó el movimiento en el contexto de reorganización partidaria ordenado por Juan Domingo Perón ${ }^{6}$ en 1963.7 Asimismo, se observa en es-

5. Recordemos que estos semanarios llegaron a tener una tirada superior a los 30.000 ejemplares por número. Además, contaba con un grupo de prestigiosos colaboradores como Rogelio García Lupo, Pedro Barraza, Julio Notta, Álvaro Ábos, Germán Rozenmacher, Ricardo Carpani, Juan José Hernandez Arregui, Rodolfo Ortega Peña y Eduardo Luis Duhalde entre otros.

6. Juan Domingo Perón había ocupado la presidencia en Argentina entre 1946 y 1955, cuando fue derrocado por un golpe de Estado. A partir de entonces, estuvo confinado al exilio hasta 1972 , y la fuerza política a la que representaba proscripta por dieciocho años.

7. Catalina Smulovitz (1988) ha señalado la importancia que tuvo este proceso de reorganización partidaria para tos semanarios la intención de mostrarse como una tribuna federal del peronismo en donde los y las referentes provinciales pudieran difundir sus reivindicaciones y sus formas de ser y estar en el peronismo.

En los siguientes apartados se analizan las marcas de autoridad que se despliegan en las páginas del semanario 18 de marzo -antecedente de Compañero-, y el contenido de sus proyecciones políticas. En segundo término, se exploran los cambios de posición que se advierten en Compañero en relación con las elecciones presidenciales de julio de 1963, y el posterior proceso de reorganización partidaria ordenado por Perón. Luego se examinan comunicaciones de mujeres peronistas publicadas en este semanario que complejizan el examen sobre el proceso organizativo en ciernes, y el lugar de las mujeres en él. Finalmente, se abordan las tomas de posición respecto a las contiendas políticas que se dieron entre los distintos sectores del movimiento en el marco de las elecciones internas de julio de 1964.

\section{8 de marzo}

La difusión del semanario 18 de marzo en quioscos y diarios de revistas el 19 de diciembre de 1962 pareció darle revancha a Mario Valotta luego de la clausura de su periódico Democracia en julio de ese mismo año. En las páginas de este último no solo había publicado colaboraciones del líder del movimiento proscripto bajo el seudónimo "Descartes", sino también, había apoyado abiertamente la postulación de Andrés Framini como candidato a gobernador de la provincia de Buenos Aires

los planes de Perón incluso por encima de las elecciones generales de 1962. 
con el sello electoral Unión Popular. ${ }^{8}$ Valotta, un hombre que había integrado el grupo de asesores de Arturo Frondizi, se alejó de las filas de la UCRI al constatar la distancia entre las promesas de campaña y las prácticas represivas del gobierno radical, que junto con su política petrolera y las iniciativas para privatizar la educación pública superior, lo alejaban de los planteos antes propugnados por la defensa del patrimonio nacional. Las críticas al gobierno frondicista (1958-1962), junto con su apoyo explícito al peronismo, le valieron la incautación de su periódico y una breve temporada en prisión. Ya en libertad, inició las gestiones para continuar con su empresa periodística explicitando su opción por el peronismo.

\section{La diagramación del semanario 18 de marzo} emulaba a la de su predecesor, como posteriormente lo hará Compañero. De tamaño "sabana”, en la portada siempre era publicada una editorial de Valotta en la que sentaba posición sobre los problemas de la coyuntura política local y el curso que debía adoptar el peronismo en sintonía con los designios de Perón.

La publicación desde su título proyectaba una marca. Evocaba en su nombre el día de la victoria electoral del peronismo que, a pesar de las proscripciones, demostraba su actualidad y capacidad para movilizar adhesiones. Desde su aparición en diciembre de 1962 hasta su noveno y último número, en febrero del año siguiente, intentó posicionarse como órgano

8. Dadas las restricciones que aún pesaban sobre el Partido Justicialista, el peronismo optó por participar en los comicios con el sello electoral de la Unión Popular. Esta fuerza política se había constituido luego del golpe de septiembre de 1955, bajo la dirección del exministro Atilio Bramuglia y desde su formación la agrupación tuvo como objeto constituir una alternativa institucional frente al estado de proscripción que sufría el peronismo. Véase: Marcilese (2014). oficial de prensa del peronismo. En ese sentido pueden interpretarse las adhesiones de distintos espacios políticos vinculados al movimiento proscripto publicadas en el semanario celebrabando la aparición de 18 de Marzo. ${ }^{9}$

En el número 6 se reproduce en la portada una epístola de puño y letra del líder exiliado dirigida a Valotta, en la que se solidariza con el director de Democracia por la clausura del semanario. La carta recibida en septiembre, publicada en enero del año siguiente, fue considerada por los colaboradores de 18 de marzo como un "reconocimiento que nos llenó de orgullo y de entusiasmo para continuar bregando por la causa del pueblo".$^{10}$ La respuesta del director del semanario al expresidente también fue publicada en la portada. En ella, expresaba: "La acción desarrollada desde la dirección de Democracia, que asumí después de la violación de la voluntad popular expresada el 18 de marzo, constituyó una inolvidable experiencia, a la vez que me permitió conquistar un puesto de lucha junto al pueblo que no abandonaré jamás”. La apelación a la epístola de Perón era una forma de legitimar las posiciones del mentor del semanario y de la publicación misma.

9. Repudio a la clausura de Democracia JP provinciales (26 de diciembre de 1962). 18 de marzo, p.1. Centro de Documentación e Investigación de la Cultura de Izquierdas (CeDInCI), Buenos Aires. El "Frente de Liberación Nacional" consideraba a 18 de Marzo "la única trinchera periodística en lucha por la liberación Nacional, Popular y antimperialista”. En el periódico La semana, de Saladillo, celebraban la aparición del semanario de Valotta, a quien consideraban "uno de los periodistas más valientes y esclarecedores del momento actual”. Saladillo. Otro puesto de lucha (15 de enero de 1963). 18 de marzo, p. 6.

10. Carta de Perón. Apoya nuestra lucha (22 de enero de 1963). 18 de Marzo, p.1. 
Del mismo modo, puede interpretarse la denuncia que Valotta realizaba sobre las persecuciones sufridas por sostener desde su periódico la vigencia del peronismo. Esta última cuestión, lo hermanaba con la experiencia de militancia forjada por el peronismo resistente, $y$ habilitaba un canal adicional para empatizar con sus potenciales lectores. El énfasis en la lucha plasmada en las páginas de Democracia, junto con el trato personal que manifiesta mantener con Perón a través de la correspondencia publicada, puede leerse como el despliegue de credenciales de un personaje relativamente nuevo en la cosmogonía del movimiento, y un intento por visibilizar ante el auditorio peronista un lugar de enunciación a través del cual interpelarlo.

Valotta ponderaba la movilización popular como protagonista del proceso abierto, nervio dinámico del peronismo proscripto, condensador de las reivindicaciones y demandas de los sectores populares del país. Ese peronismo, enriquecido por la experiencia de lucha, había articulado a través de los sectores más combativos del movimiento obrero un programa de acción política que, desde su perspectiva, era la brújula de las acciones a emprender. E1 decálogo sancionado en la localidad cordobesa de Huerta Grande fue, en lo sucesivo, considerado por 18 de marzo y, posteriormente, por Compañero, como la guía programática del peronismo revolucionario. Por su parte, Andrés Framini quien había sido electo en 1962 como gobernador de la provincia de Buenos Aires resultó continuamente reivindicado por estas publicaciones como el máximo referente político y sindical del movimiento proscripto. ${ }^{11}$

11. Framini, A. (5 de febrero de 1963). Somos el estado mayor del ejército del pueblo. 18 de Marzo, p. 5. La elección de Framini en 1962 no fue reconocida por el gobierno de Frondizi quien, a su vez, fue derrocado en el mismo año.
Asimismo, el semanario destacaba el paulatino acercamiento de los sectores medios y, fundamentalmente, de la juventud al peronismo como un signo de la madurez del proceso revolucionario existente en el país.

Otras cuestiones que se destacan en el semanario, y que tendrán continuidad en la etapa de Compañero, refieren a la centralidad del rol político del sindicalismo en la vigencia del peronismo y en la importancia de las bases obreras en él. La nota de Valotta en torno a la normalización de la central obrera de enero del '63 es representativa de una línea editorial que trascenderá la existencia de 18 de marzo. En ella, el director del semanario planteaba:

La labor de los dirigentes comienza ahora. Es su obligación impostergable establecer un estrecho contacto con las masas, abandonando la actitud burocrática, para acelerar las tareas de la movilización que exigen incorporar constantemente nuevas formas de lucha para eludir el cerco de la reacción y enfrentar con éxito la violencia creciente. La opinión y las ideas de los hombres de base permitirán ampliar la propia perspectiva y a la vez crear nuevos métodos organizativos que sumen a la acción a la joven generación de militantes. ${ }^{12}$

Desde esta perspectiva, el movimiento obrero organizado ya unificado debía impulsar a través de su dirigencia la movilización popular como único camino para acelerar los cambios políticos necesarios para el retorno del peronismo al poder del Estado. Dentro de esta interpretación, el "pueblo" es concebido como el nervio profundo que impulsa las acciones a adoptar por los dirigentes sindicales, devenidos en políticos por la fuerza de las circunstancias.

12. La trampa no camina (5 de febrero de 1963). 18 de Marzo, p.1. Negritas en el original. 
Por ello, las cúpulas sindicales debían subordinarse al mandato de sus bases y abandonar cualquier posición que cercene las intenciones de aquellas.

De allí también que el grado de combatividad de los y las trabajadores y de las conducciones obreras fuera constantemente arengada en 18 de marzo, como también en Compañero, en tanto índice de la radicalidad alcanzada por las bases del movimiento. En sus páginas se informaba sobre los posicionamientos políticos $\mathrm{y}$ sindicales de referentes obreros de distintas regiones del país, quienes además de comunicar la problemática de su sector, ${ }^{13}$ señalaban cuales debían ser las acciones que las cúpulas sindicales debían adoptar para solucionar los problemas de los trabajadores, e incluso brindaban espacios a nuevos referentes gremiales para comunicar sobre la creación de nucleamientos políticos en el interior de los sindicatos peronistas. ${ }^{14}$

A través de entrevistas a distintos colaboradores de estas publicaciones se ha podido reconstruir cómo esas informaciones llegaban a las páginas de estos semanarios. Grupos políticos y sindicales peronistas de la tendencia combativa hacían llegar a la redacción de 18 de marzo,

13. Gremialismo a todo pulmón (8 de enero de 1963). 18 de marzo, p. 6. Juan Rojic, dirigente textil de base: "Mi responsabilidad comienza ahora" (15 de enero de 1963). 18 de marzo, p. 5. "Nada impedirá el ascenso de las masas al poder", entrevista a Benito Romano (5 de febrero de 1963). 18 de Marzo, p. 6. Reportaje de la semana: Jorge Di Pascuale [sic] (22 de enero de 1963). 18 de marzo, p. 8.

14. Visitas: justicialistas de la construcción (22-011963). 18 de Marzo, p. 6. Se informa sobre la iniciativa de Humberto Aguirre (delegado por Córdoba) y de Roberto Sosa (Tucumán) de crear un Movimiento Sindical Justicialista (MSJ), en oposición al Movimiento de Defensa Sindical (MDS) de la Unión Obrera de la Construcción. y posteriormente de Compañero, crónicas sobre los conflictos y reivindicaciones que llevaban adelante. En un contexto de clausura informativa para el peronismo, estos semanarios resultaban los únicos canales informativos a través de los cuales difundir las luchas y problemas de los peronistas. Además, estas publicaciones, a diferencia de otras, podían comprarse en kioscos de diarios y revistas, e incluso era posible solicitar su envío por correo a través de subscripciones, lo cual ampliaba su difusión. ${ }^{15}$

La cercanía con Perón como el haber purgado prisión por la defensa de la causa peronista fueron siempre elementos que se mencionaban al presentar reportajes de referentes políticos y sindicales. En el caso de Pedro Gallo, además de los elementos antes mencionados, se informaba que era "miembro directivo de la Seccional Ciudadela de la Unión Obrera Metalúrgica y concejal electo en las elecciones del ya celebre 18 de marzo de 1962 ". ${ }^{16}$ Esta mención antecede a la pregunta acerca de “¿cuál es la misión de la clase obrera en la lucha por la Liberación Nacional?". Nos preguntamos si acaso esa interrogación no contiene un "deber ser", una "misión" a cumplir por los trabajadores. Esa expectativa se ve confirmada en la respuesta de Gallo, quien incluso apela al pasado para explicar el lugar de los trabajadores en las luchas del presente:

Los antecedentes históricos a partir de las invasiones inglesas ponen en evidencia el papel decisivo que el pueblo trabajador, en sus distintas formas de organización a través de las épocas, jugo un papel fundamental en

15. Entrevista a Hugo Chumbita realizada por Valeria Caruso, febrero de 2018; entrevista a Mario Tesler realizada por Valeria Caruso, marzo de 2018.

16. Hoy Pedro Gallo metalúrgico: el país sentado en un polvorín (29 de enero de 1963). 18 de Marzo, p.5. 
procura de la libertad política de la nación, y no sería de extrañar que en un futuro no muy lejano, por no decir inmediato, los trabajadores junto con otras fuerzas del país que los acompañaran, den la última batalla por la liberación nacional, que lógicamente se verá coronada por el éxito.

Veamos aquí como la acción activa del pueblo ha construido la nación y la ha liberado de sus antiguas ataduras. Fijémonos que la palabra "pueblo" se presenta al inicio de la argumentación como equivalente a la palabra "trabajador" para dar cuenta de la continuidad de aquel en las luchas del presente. La igualación de ambos términos posiciona a los trabajadores y trabajadoras como continuadores de ese pueblo que en el pasado logró la liberación, y que se reactualiza en la acción de los obreros y obreras argentinas por la emancipación. Esta respuesta confirma la pregunta, e incorpora el pasado histórico nacional como una fuente de verdad a los argumentos vertidos.

En 18 de marzo la exhortación a la juventud tuvo un lugar destacado. Desde sus páginas, se apelaba a la visualización de ese actor como potencial aliado del proletariado peronista. ${ }^{17}$ Como se señaló anteriormente, la vinculación de las juventudes con el peronismo fue considerado entonces como un índice de maduración del proceso político abierto.

En sentido, resulta representativa la transcripción de una carta de un joven preso en el marco del Plan Conmoción Interna del Estado (en adelante, CONINTES) decretado por Frondizi, quien decía reconocer en 18 de marzo la

17. J.N.S. 'Patria o Muerte' (8 de enero de 1963). 18 de marzo, p. 4. También se publican adhesiones de la JP Bahía Blanca y del comando Devoto de la JP Capital Federal en: Más juventudes (5 de enero de 1963). 18 de marzo, p. 6. trinchera informativa del peronismo proscripto. ${ }^{18} \mathrm{La}$ exaltación del heroísmo del escribiente era la contracara de la "cómoda" situación desde la cual los universitarios rechazaban al peronismo: "Parecería que estos muchachitos estudiantes quisieran mantener la Universidad en su torre de marfil para que no les llegue el "lodo" hediondo de las villas miserias, donde nuestra oligarquía mantiene hacinados a los trabajadores argentinos". A continuación, se reproducía en la misma página una carta de un estudiante universitario -de quién no se explicita el nombre- que pareciera entrar en dialogo con la anterior: "en este 1962 que nos ha tocado vivir aprendí muchas cositas entre ellas, el interesarme realmente por los problemas de mi pueblo, al analizarlos, ya dentro de mi campo de acción, tratar de agregar mi granito de arena para ayudarnos mutualmente".$^{19}$ Nótese la similitud de este planteo con las exhortaciones a los universitarios antes realizadas por el joven preso CONINTES. En esa línea, y con el título "Crisis del sistema universitario", se describía y cuestionaba los posicionamientos de las organizaciones estudiantiles humanistas, ateneístas y de "izquierda" reformista respecto a los intereses y reivindicaciones del pueblo, en los siguientes términos

los militantes reformistas que tienden a ligarse con el movimiento nacional soportan el ataque de la 'izquierda' reformista (reformista en doble sentido) que los tilda de 'ultraizquierdistas', raro modo de reconocer que en nuestro país la izquierda es el pueblo peronista y los que giran a la izquierda son los políticos que tienden a acercársele. ${ }^{20}$

18. Carta de un CONINTES (8 de enero de 1963). 18 de marzo, p. 4.

19. Hay que definirse (8 de enero de 1963). 18 de marzo, p. 4.

20. La crisis del sistema universitario (8 de enero de 
Este fragmento nos ilustra sobre el paulatino acercamiento de un sector del estudiantado al movimiento proscripto. También da cuenta de una nueva concepción del peronismo que lo sitúa como la verdadera izquierda argentina destacando que los 'otros', la 'falsa izquierda', son quienes no han advertido que el peronismo es el pueblo y que donde está el pueblo está la izquierda.

No obstante, ese sentido atribuido al peronismo no será unívoco entre sus militantes. Tal como puede observarse en la entrevista realizada por Pedro Barraza a referentes de la juventud peronista. ${ }^{21}$ Entre los entrevistados se encontraban Héctor Mel (22 años), Alejandro Alvarez (25 años), Rodolfo Cruzado (24 años), Edgardo y Hugo (de quienes no se publican sus apellidos por cuestiones de seguridad), todos ellos integrantes de la "Comisión Reorganizadora de la JP”. Este organismo, según argumentaban, tenía a su cargo la fusión de "todas las publicaciones de los distintos núcleos que ahora están representados en la Comisión Provisoria Reorganizadora -Trinchera, Guardia de Hierro, Revolución Peronista- para expresarse a través de un solo órgano de mayor envergadura", y la tarea de "consolidar la reunificación de las JP, ampliar las bases juveniles y perfeccionar el aparato organizativo". Según manifestaban, todas estas acciones fueron ordenadas epistolarmente por Perón. Ese vínculo con el el ex presidente pareciera habilitar, además, un reclamo por la participación de la JP en el órgano de conducción del peronismo local, es

1963). 18 de marzo, p. 4. En números posteriores se publican cartas de lectores adhiriendo a estas posiciones, véase: La torre de Marfil (5 de febrero de 1963). 18 de marzo, p. 6.

21. Reportaje a la Juventud Peronista (29 de enero de 1963), 18 de Marzo, p. 8. decir, en el Consejo Coordinador Supervisor (en adelante, CCS). Para lo cual, enuncian otra marca de autoridad con la que intentan avalar la relevancia de la novel organización en función de su cercanía con Framini, de quien dicen ser "estrechos colaboradores".

Para estos jóvenes militantes si bien "los sucesos posteriores al ' 55 hicieron rever a muchos su equivocada postura 'antiperonista', inclusive sacudieron viejos esquemas de la "izquierda tradicional", la cercanía del peronismo con las izquierdas debía de ser limitada. Reconocían que "18 de marzo era una necesidad imperiosa del pueblo: la de hacer oír su voz a través de un vocero de carácter nacional. Más si 18 de marzo desea interpelar fielmente el pensamiento nacional debe cesar de aceptar colaboraciones de individuos pertenecientes a la izquierda". La respuesta del semanario era publicada al final de la entrevista: "En cuanto al compañero Edgardo le decimos que rechazamos cualquier exclusión de tipo "macarthista". ${ }^{22}$ No nos interesa el origen de nuestros colaboradores cuando sabemos que son hombres que también luchan sinceramente por la liberación nacional". En este dialogo se aprecian dos perspectivas. Por un lado, los jóvenes referentes del peronismo advierten un cambio de posición de las izquierdas "tradicionales" respecto al peronismo, al mismo tiempo que descartan una vinculación estrecha entre éstas y el movimiento proscripto. Mientras que 18 de Marzo, además de intentar posicionarse como un órgano de prensa legitimo para el peronismo -algo que reconocen los entrevistados y otros militantes peronistas-, parece auspiciar conexiones entre la fuerza política prohibida y aquellas expre-

22. La expresión "macarthista" refiere a situaciones en las que se acusa, persigue y excluye a contrincantes políticos bajo la sospecha de "comunistas". 
siones de las izquierdas que encuentran en el peronismo una vía para la trasformación de la sociedad argentina.

Esa respuesta también será enunciada para responder a otras imputaciones en las que los lectores cuestionan la decisión del semanario de publicar colaboraciones de "liberales e izquierdistas", a pesar de reconocer en Valotta un auténtico "montonero". ${ }^{23}$ Los redactores de 18 de Marzo afirmaban entonces que sus páginas estaban abiertas para todos aquellos que "estén decididos a luchar por la liberación nacional”, sin importar su procedencia partidaria siempre que se encolumnen detrás de las reivindicaciones sostenidas por el peronismo en tanto único vehículo de la revolución nacional por hacer.

\section{Compañero y las bases obreras peronistas.}

Desde mediados de febrero de 1963, 18 de Marzo denunciaba las intimaciones que recibía del gobierno para censurar el contenido político del semanario. ${ }^{24}$ Finalmente, la publicación fue incautada y clausurada por orden del Poder Ejecutivo. Recién en junio de ese mismo año, un mes antes de la elección presidencial, aparecía en la escena pública un nuevo emprendimiento editorial dirigido por Valotta con el nombre de Compañero. ${ }^{25}$

23. Las mismas banderas (5 de febrero de 1963). 18 de Marzo, p. 6.

24. Lonjitas de Salmuera (5-02-1963), 18 de Marzo, p. 4.

25. La diagramación, tipografía y las secciones asignadas a cada página fueron las mismas que las de su predecesor. Las variaciones entre uno y otro serán analizadas en el trascurso de este apartado.
Desde su aparición, rechazó la presentación electoral del peronismo en el "Frente Nacional y Popular" impulsado por Vicente Solano Lima. ${ }^{26}$ Para el semanario, ese referente respondía a los intereses de Rogelio Frigerio ${ }^{27}$ para "reeditar la experiencia del 23 de febrero de 1958" y ganar los comicios, nuevamente, con los votos peronistas. ${ }^{28}$ Asimismo, consideraba que cualquier alianza con el "frigerismo" representaría al "flanco de la burguesía organizada en torno al 'Frente Nacional", es decir, terminaría por beneficiar a los factores de poder que se articulaban a espaldas del pueblo. ${ }^{29}$ Ante lo cual, Compañero llamaba a obedecer los memorándums numerados 4 y 5 enviados por Perón, en los que establecía acudir a elecciones con candidatos propios en el caso de que se dieran de las condiciones. De lo contrario, proponía aguardar al 25 de junio, día en el que el

26. Solano Lima tuvo una larga trayectoria en las filas del Partido Conservador, por el cual fue electo dos veces diputado y candidato a vicepresidente de la nación en 1951. En 1958, fundó junto con Alberto María Fonrouge el Partido Conservador Popular, y durante la década del '60 intentó profundizar sus vinculaciones con el peronismo. La semana política (14 de junio de 1963). Compañero, p. 3. Centro de Documentación e Investigación de la Cultura de Izquierdas (CeDInCI), Buenos Aires. Solano Lima fue un personaje recurrentemente denostado en la publicación por su "nacionalismo oligárquico y aristocratízate". Véase: Patíbulo. Hoy: Solano Lima (7 de junio de 1963). Compañero, p. 8.

27. Rogelio Frigerio periodista y político argentino vinculado a la UCRI. Fue una figura clave de la presidencia de Frondizi (1958-1962). Impulsó la alianza con el peronismo, que se materializó en el histórico pacto secreto entre Frondizi y Perón de 1958, que le posibilitó la victoria presidencial. Fue también uno de los máximos referentes del desarrollismo argentino, fundador junto a Frondizi del Movimiento de Integración y Desarrollo, en 1964.

28. El pueblo no entra (7 de junio de 1963). Compañero, p. 3 .

29. Falsa opción (7 de junio de 1963). Compañero, p. 1. 
General confirmaría la orden de la abstención de los votantes peronistas. ${ }^{30}$

Compañero intentó incidir en los márgenes de acción de la conducción local, y junto con ello, condicionar la opinión de los y las lectores sobre el proceder de los dirigentes peronistas de cara a los comicios. ${ }^{31}$ En ese sentido, resulta significativa la publicación de entrevistas a referentes políticos y sindicales de todo el país en las que vierten sus opiniones sobre el proceso político en curso, en estrecha sintonía con los postulados del semanario. ${ }^{32}$ Estas intervenciones fueron precedidas por la presentación de "credenciales" militantes de los entrevistados: se mencionaban las penas y persecuciones purgadas por sostener la vigencia del peronismo, lo cual reforzaba el grado de compromiso del hablante con la causa, al mismo tiempo que, autorizaba su opinión en función de su entrega militante. En las respuestas de los entrevistados se enfatizaba el rechazo a la opción electoral encabezada por Solano Lima, y la absoluta obediencia a las directrices establecidas por Perón en los memorándums. ${ }^{33}$

En ese contexto, Compañero informaba acerca de la apertura del semanario para que en sus páginas los peronistas expresaran su opinión ante el proceso electoral, "y hacer llegar

30. Parando la oreja (14 de junio de 1963). Compañero, p. 3.

31. Cartas (14 de junio de 1963). Compañero, p. 3; Dice Roberto Viglio: "Las farsas electoralistas son piezas de un museo de oprobio (21 de junio de 1963). Compañero, p. 5.

32. Habla Marcelo Repezza "no podemos prestarnos al juego de la antipatria: abstención es la consigna” (21 de junio de 1963). Compañero, p. 3.

33. El Comando Justicialista de la Resistencia se expresa en contra de la fórmula presidencial lanzada por el Frondizismo en favor de Solano Lima, véase: Parando la oreja (14 de junio de 1963). Compañero, p. 3.

50 de esa manera la necesaria información para que la dirección del movimiento popular tenga todos los elementos que le permitan tomar, en el momento oportuno la decisión final. Porque, como siempre, SE HARÁ LO QUE EL PUEBLO QUIERA." ${ }^{4}$ A través de esta convocatoria, el semanario intentaba afirmar su posición como el nexo comunicacional entre las bases del movimiento y su conducción. ${ }^{35}$ En esa línea, se publicaba un comunicado del Movimiento Sindical Justicialista de los Obreros de la Construcción en el que expresaban que "este movimiento luchará por la abstención revolucionaria y no votará ningún candidato extra partidario", y convocaba "a todos los sectores gremiales y sociales que desean la liberación nacional (...) a adoptar la misma posición”. ${ }^{36}$

A pesar de la intención de Compañero de incidir en las decisiones de la dirección política del movimiento a través de la opinión de las bases obreras y políticas del peronismo, el apoyo brindado por el CCS y las 62 Organizaciones $^{37}$ a la alianza electoral encabezada por Solano Lima, señalaba una primera derrota. ${ }^{38}$ Ese proceder fue interpretado como una traición de las burocracias políticas y sindicales del peronismo que le hacían "el juego al gobierno"

34. Se hará lo que el pueblo quiera (14 de junio de 1963). Compañero, p. 1. Mayúsculas en el original.

35.Pese a quién pese y caiga quien caiga ( 28 de junio de 1963). Compañero, p. 6.

36. Repudian el frente. La reacción de las bases (21 de junio de 1963). Compañero, p.4.

37. La denominación refiere a las 62 organizaciones sindicales peronistas.

38. Las bases interpretan a Madrid: VOTO EN

BLANCO. 62 orden mal entendida (5 de julio de 1963).

Compañero,pp. 1-5. 
en vez poner en actos la decisión de las bases y de Perón ordenando el voto en banco.

En ese contexto, el gobierno de José María Guido (1962-1963) ${ }^{39}$ tomó nuevas medidas para condicionar la reedición de la Unión Popular una semana antes de los comicios. ${ }^{40} \mathrm{Re}$ cién entonces se oficializó la orden de Perón exigiendo la abstención. Finalmente, el voto en blanco alcanzó un módico 19\%, poniendo en evidencia la merma de la influencia del peronismo en el escenario político local, junto con el naufragio de candidaturas peronistas y la eventual y sorprendente victoria de Arturo Illia, quien gobernó entre 1963 y 1966 (Mathias, 2017 p. 176). ${ }^{41}$

Para Compañero el triunfo del candidato de la Cívica Radical del Pueblo (UCRP) fue facilitado por la dirección local del movimiento que dilató la difusión de la orden de Perón de votar en blanco, lo cual contribuyó a la desorientación del electorado peronista. ${ }^{42}$ El semanario denunciaba, además, que el proceder de la rama política fue consentido por la cúpula sindical que abortó la huelga general pautada para el viernes previo a las elecciones. Lo cual demostraba la falta de representatividad del alto mando sindical en relación con las inten-

39. José María Guido asumió el gobierno en Argentina luego del derrocamiento de Arturo Frondizi como consecuencia de un golpe de Estado.

40. Decreto/Ley 5069/1963, Poder Ejecutivo Nacional, Boletín Oficial del 28-06-1963, n²0157.

41. Arturo Humberto Illia fue depuesto en junio de 1966 por un golpe de Estado encabezado por el general Juan Carlos Onganía quien sería presidente de facto de Argentina hasta 1970.

42. Una nueva etapa (16 de julio de 1963). Compañero, p. 1. Denuncian que "durante casi una semana la orden de voto en blanco buscando un 'permiso' oficial hasta último momento para convalidar el fraude". ciones de los trabajadores que rechazaban una convocatoria de esa índole, terminando por "arrinconar el programa de Huerta Grande por no seguir la orientación que les marcaron en todo momento las bases populares". ${ }^{43}$ Las comunicaciones de los lectores publicadas en sus páginas, reforzaban los juicios emitidos por Compañero criticando a la conducción local del movimiento por los resultados de los comicios. $^{44}$

Melon Pirro (2011) ha planteado que luego de las elecciones presidenciales de 1963, no sólo se aceleró la caída de la popularidad del CCS, sino que también, se incentivó el accionar crítico de los "peronistas díscolos" respecto del organismo de conducción del movimiento. Esto, a su vez, incidió en el proceso de reorganización partidaria ordenado por Perón para contener esa dispersión. Ese proceso se visualiza en Compañero en tres sentidos..$^{45}$ En primer lugar, la apelación permanente a las bases peronistas como la auténtica voluntad revolucionaria del movimiento y, por lo tanto, poseedora de la potestad para dirimir la representatividad que se disputaban los distintos referentes. En segundo lugar, y vinculado con lo anterior, la imposibilidad de contener al movimiento dentro de las formalidades de los partidos políticos tradicionales. En tercer término, la caducidad de los dispositivos de la democracia formal para lograr el retorno del peronismo al poder del Estado.

43. La protesta quedo en el tintero (16 de julio de 1963). Compañero, p. 3 .

44. Aguirre: los dirigentes no funcionan (16 de julio de 1963). Compañero, p. 3. Cartas (23 de julio de 1963). Compañero, p. 6. Cartas (30 de julio de 1963). Compañero, p. 4.

45. Polarización (23 de julio de 1963). Compañero, p. 1. 
Estos entendimientos se sustentaban, en parte, en relación con la información que trascendía de distintas reuniones partidarias. Por ejemplo, Compañero informaba sobre "las asambleas y las reuniones de los activistas del movimiento del interior y del Gran Buenos Aires, de los sindicatos y organismos juveniles, [que] marcan la necesidad de pasar a la acción. ${ }^{46} \mathrm{Re}-$ clamaban una conducción revolucionaria que no claudique ante "los objetivos revolucionaros compartidos tanto por Madrid como por la clase trabajadora argentina". ${ }^{47}$ También comunicaba el desarrollo de "numerosas reuniones realizadas por Centros Justicialistas de todo el país, [en las que] se criticó abiertamente a los directivos de las 62 y al Consejo Supervisor". ${ }^{48}$ Otra situación similar se presentó en el congreso partidario celebrado en la localidad bonaerense de las Flores, en el que "Miguel Gazzera fue expulsado violentamente al pretender coparlo con un grupo de matones capitaneados por Caffiero [sic]". ${ }^{49}$

Para el semanario, esas actitudes demostraban el grado de "esclarecimiento de la base no permite que ningún aventurero o agente divisionista tipo Matera pueda capitalizar en

46. La bola de nieve que arrasa con todo (30 de julio de 1963). Compañero, p. 1.

47. Véase también: Jujuy: la hora de la verdad (27 de agosto de 1963). Compañero, p. 6.

48. Los 'lobos' disfrazados de corderos serán desplazados de nuestro movimiento (30 de julio de 1963). Compañero, p. 3. En similares términos se expresaban los militantes de la localidad bonaerense de General Sarmiento en: Hablan justicialistas de Gral. Sarmiento. Reorganización de abajo hacia arriba (30 de julio de 1963). Compañero, p. 6. Como también los miembros del Movimiento Doctrinario Justicialista de la ciudad santafecina de Rosario: Rosario. Una actitud crítica (27 de agosto de 1963). Compañero, p. 6.

49. La semana política (6 de agosto de 1963). Compañero, p.3. provecho propio el justificado descontento de las masas con la conducción de la troica Vandor-Olmos-Gazzera". ${ }^{50}$ La crónica publicada sobre el congreso justicialista de Las Flores, enfatizaba la bronca y el recelo con el que más de mil peronistas expulsaron a Gazzera, ${ }^{51} \mathrm{y}$ neutralizaron las intenciones de Raúl Matera de monopolizar la reunión. Además subrayaban algunas intervenciones de los congresales que se vinculan estrechamente con los postulados políticos que sostenía Compañero. Por ejemplo, la del delegado de la "seccional 17 de la Capital”, quien planteó que "[e]1 Movimiento Peronista debe estructurarse como partido revolucionario". Otro de Tres de Febrero afirmó que "[1] a nuestra es la rebelión de las bases que reclaman la unidad del Movimiento." Los miembros de la Junta de Distrito del Movimiento Justicialista del Partido de la Matanza denunciaban los intentos de ciertos dirigentes- como Chambón y Gazzera- de "romper aquel intento de las bases de expresarse contra la conducción del Consejo Coordinador y en favor de la reorganización del partido Justicialista". ${ }^{52}$

50. Augusto Timoteo Vandor fue secretario de la Unión Obrera Metalúrgica (en adelante, UOM). Desde su posición sindical, denominada "vandorismo", cimentó su liderazgo político en el interior del peronismo.

51. Las Flores. El “matterismo" fracaso. Sillazos para los dirigentes (6 de agosto de 1963). Compañero, p. 5. Según relatan, Gazzera habría terminado colgado de un árbol para sortear el linchamiento de los militantes. Informan que Matera habría contratado micros para acarrear personas hasta la reunión para que apoyen sus posiciones “occidentales y cristianas". Recordemos que Matera fue expulsado del Movimiento Peronista luego de que presentara su candidatura a presidente de la nación por el Partido Demócrata Cristiano. Hasta ese momento había oficiado como vocero de Perón y miembro del CCS.

52. La verdad sobre 'Las Flores' (20 de agosto de 1963). Compañero, p. 4. 
Compañero incentivaba "la rebelión de las bases" frente al CCS y a las cúpulas sindicales de las 62 Organizaciones, e intentaba incidir en la ampliación "de la línea revolucionaria [que] debe entonces extenderse a todos los planos del movimiento: sindicatos, organismos políticos y de la juventud, [y] debe reflejar orgánicamente la nueva tendencia de las bases," e impulsar la "definición ideológica y política que debe ser el eje en torno del cual se nucleen los elementos más combativos en todos los niveles," y terminar "con todos los oportunistas, algunos elementos de derecha". ${ }^{53}$ Aquí se advierte un "deber hacer" para los sectores "esclarecidos" en un contexto que se cree propicio profundizar la línea revolucionaria. Se demandaba entonces una coordinación de esfuerzos para ampliarla y difundirla, y así desterrar definitivamente del movimiento a las dirigencias que desviaban las reivindicaciones de las bases. En el alegato de Valotta, estas tareas se presentan como la manera de desplazar a los elementos que eran percibidos como la derecha del peronismo. Y por oposición, consolidar la posición de los sectores combativos, que expresaban el ala izquierda del movimiento. ${ }^{54}$

Pero volviendo al convulsionado proceso de restructuración partidaria del peronismo, resulta oportuno examinar cómo se reposicionaron los actores y, sus discursividades, al conocer la designación de un nuevo organismo deno-

53. La Rebelión de las bases (6 de agosto de 1963). Compañero, p. 1. Recordemos que la apelación a la "rebelión de las bases" será la consigna nodal de la experiencia obrera que se concitará cinco años después en la CGT de los Argentinos.

54. Sí bien las tensiones y debates entre izquierdaderecha alcanzaron su estadio más alto durante la década del '70, la aparición de demarcaciones discursivas que apelan a esas posiciones puede rastrearse en el interior del peronismo desde fines de la década del ' 50 , tal como desarrolle en mi tesis doctoral (Caruso, 2019). minado "Comisión Interventora Nacional" más conocida como "Cuadriunvitaro", que sin reemplazar al CCS, tuvo la tarea de reorganizar el partido "de abajo hacia arriba", sin más exclusiones que las de Matera. Este nuevo ente liderado por Framini, e integrando por Julio Antún -secretario de Difusión y Prensa-, Ilda Pineda de Molina -secretaria de finanzas-, y Rubén Sosa -secretario de Organización e Interior-, parecía atender a las demandas que las bases del movimiento expresaban a través del semanario.

Compañero celebraba entonces la designación del líder de textil al mando del nuevo organismo, ${ }^{55} \mathrm{e}$ informaba sobre las giras por el interior del país que los integrantes del cuadriunvirato llevarían adelante para acoger las demandas de las bases. ${ }^{56}$ También publicaban textos firmados por Framini exhortando a la "Revolución Peronista", ${ }^{57}$ y comunicados del nuevo organismo en donde expresaban que "el PERONISMO tiene una misión trascendente y revolucionaria que supera los límites de la política tradicional porque incorpora a las masas populares a la lucha por la EMANCIPACIÓN NACIONAL". ${ }^{58}$ Aunque para Companero, como para otros actores que se expresan en sus páginas, el proceso de reorganización no debería conducir a la institucionalización del

55. Framini al Timón (10 de septiembre de 1963). Compañero, p. 1.

56. Parando la oreja (10 de septiembre de 1963). Compañero, p. 3. Córdoba. El sin calumnia al cuadrunvirato (9 de octubre de 1963). Compañero, p. 5.

57. Reorganizar el movimiento desde abajo (16 de octubre de 1963). Compañero, p. 6.

58. Cuadrunvirato. $\mathrm{El}$ peronismo desconoce al gobierno del fraude (9 de octubre de 1963). Compañero, p. 4, mayúsculas en el original. Comisión interventora Justicialista. Organizar el partido de abajo hacia arriba (30 de octubre de 1963). Compañero, p. 4. 
peronismo como un partido político más, sino que el cuadriunvirato debía funcionar como el vehículo para lograr la unidad del movimiento, que permitiría la recuperación del poder del Estado para realizar la revolución peronista que las masas demandaban. ${ }^{59}$

\section{Las mujeres en Compañero}

En ese contexto, el semanario instaba a las peronistas a "tomar en sus manos la bandera revolucionaria que dejó Evita" y sumarse a las luchas por la vigencia del movimiento. ${ }^{60} \mathrm{~A}$ partir de entonces, Compañero cedía un espacio para que las mujeres que se identificaban con el movimiento proscripto. Consideraban que "en fábricas, talleres y oficinas hay millones de mujeres peronistas, de trabajadoras que, a las siete, ocho y nueve horas de labor, por un salario agregan varias más de trabajo doméstico, para el esposo, los hijos o la familia" que debían ponerse en contacto para encontrar soluciones a problemáticas compartidas. Estas no se restringían a la órbita del trabajo formal, sino también, a esa doble responsabilidad con la que las mujeres cargaban en relación con el trabajo doméstico no remunerado como condicionante de las responsabilidades femeninas. Aunque se menciona la cuestión, no se vuelve sobre ella para problematizarla, sino para dar cuenta de la existencia de obligaciones que convierten al involucramiento político de las

59. ¿Cómo se reorganizará el justicialismo? Cuatro medidas previstas y una condición 'sine qua non' (17 de septiembre de 1963). Compañero, p. 4.

60. Con Evita, otra vez en la lucha (24 de octubre de 1963). Compañero, p. 3. Aunque no se explicita la adscripción de las peronistas convocantes, conjeturamos que estas intervenciones podrían vincularse con la intención de emprender la reorganización de la rama femenina. Recordemos la participación de Ilda Pineda de Molina en el cuadriunvirato. mujeres, mucho más loable. También para evidenciar que la resolución de esos problemas comunes se encontraba en "en la lucha, y para luchar precisamos reunirnos, organizarnos y aprender a golpear donde más duela”.

La "página femenina de Compañero" se inauguraba con la carta de "una metalúrgica peronista", en la que describe su cotidianeidad, los avatares de la vida doméstica combinada con el trabajo fuera del hogar, y los problemas que se presentan en la fábrica en la cual era delegada de sección. ${ }^{61} \mathrm{El}$ relato del accionar de esta obrera resulta ejemplificador y modélico: una mujer que se organiza para cumplir con sus quehaceres domésticos, ser una buena trabajadora, y además, defender sus derechos y los de sus compañeras en la fábrica. Aunque la realización de las tareas domésticas no era cuestionada, se la presentaba como un aditamento de las obligaciones femeninas que no necesariamente debían inhibir la participación política y gremial de las mujeres.

Desde entonces, hasta la realización de las elecciones internas del justicialismo, se reiteraron las comunicaciones de distintas referentes políticas y sindicales de diversas zonas del país anunciando sus actividades y posicionamientos frente al proceso de reorganización abierto. ${ }^{62}$ Por caso, se publica una carta de la "Comisión femenina peronista del Chaco Santiagueño" en la que al mismo tiempo que celebran la convocatoria de la "Comisión Femenina Nacional de Promoción de Bases", denunciaba que

61. Compañera. Con la Bandera de Evita (6 de noviembre de 1963). Compañero, p. 6.

62. Adelante, compañera (21 de enero de 1964). Compañero, p. 6. General Sarmiento: gran Actividad peronistas (27 de enero de 1964). Compañero, p. 6. Tucumán: con la Bandera de Evita (10 de marzo de 1964). Compañero, p. 8. 
Por estos lados, las mujeres peronistas hemos sido totalmente excluidas del Movimiento donde solo se nos ha permitido votar para los candidatos designados. Todo lo hicimos con Disciplina y Resignación. Ahora, se habla de promisiones de bases. Y nosotros nos preguntamos... ¿Qué papel jugamos las mujeres Peronistas de tierra adentro en esta partida...?

Ustedes que están en la "boca del lobo", ¿pueden señalarnos el derrotero a seguir...? ?3 $^{63}$

Estas mujeres expresaban ser marginadas de las decisiones que se adoptaban en el plano local, y denunciaban solo ser tenidas en cuenta al momento de la votación. A pesar de haber acatado las ordenes impartidas con "disciplina y resignación", no se las consideraba para conformar las candidaturas de su distrito. Manifestaban ser excluidas sistemáticamente de los espacios de poder local. Acudían entonces al llamado realizado por Compañero con la intención de hacer pública y visible esa situación particular, aunque también, con la expectativa de que ese comportamiento fuera corregido.

Reclamos similares se ponían de manifiesto en las comunicaciones que otras peronistas hacían llegar al semanario. Por caso, María Antonia Salomón, directora del periódico Abanderada, mencionaba haber pasado "días inolvidables de cárcel" en defensa de la causa, y de nunca "haber usufructuado jamás privilegios ni beneficios de ninguna índole ni especie". ${ }^{64}$ Llama-

63. “Compañera ¡Por la Patria y por Perón! (4 de febrero de 1964). Compañero, p. 5. Mayúsculas en el original. Las firmantes de esta comunicación son Venancia Gómes, Irma Ravelo y Celia M. de Zapella.

64. Organizar al Movimiento (11 de febrero de 1964). ba a depurar el movimiento de los dirigentes entreguistas, a renovar los principios del peronismo para consolidar la reorganización partidaria y así construir la unidad necesaria para su triunfo.

En ese sentido también se expresaba Elisa López, integrante de la Lista Verde, y de la Rama Femenina de Salta, quien decía propugnar desde su organización -"vinculada a las 62 Organizaciones, un sector de prestigiados dirigentes políticos y de la entusiasta y valiente JP" - por un "peronismo popular", opuesto al peronismo que prevalecía en su provincia "siempre dirigido por tres o cuatro familias tradicionales de muchos apellidos y ninguna sensibilidad popular." ${ }^{65}$ Ese Peronismo popular al que refería, era el que identificaba con un el sector del movimiento "que viene siendo postergado una y otra vez por la acción de ciertos dirigentes que se perpetuaron en la conducción del partido". Para López, ya no era posible una "salida electoral" porque desde "[e]1 17 de julio se ha cerrado el ciclo de las farsas electorales, se ha cerrado también para el peronismo todos los caminos de la legalidad y se le abrió el único por el cual puede seguir: el de la insurrección popular como medio para tomar el Poder y así llevar a cabo la gran Revolución Social que el Pueblo Argentino necesita”.

En similares términos se expresaba Rosario M. de Romero, militante peronista cordobesa y miembro de la rama femenina de la primera hora. ${ }^{66}$ Romero decía haber participado como delegada por la provincia de Córdoba en el

Compañero, p. 6.

65. Salta: con las banderas de Evita (11 de marzo de 1964). Compañero, p. 6.

66. Organizarse para la lucha (27 de enero de 1964). Compañero, p. 5. 
Primer Congreso Femenino Peronista realizado en la ciudad de Buenos Aires en 1949, año en el que fundó la unidad básica que coordinaba desde entonces en la localidad cordobesa de General Valle. Destacaba en este reportaje que las mujeres peronistas "hace tiempo que ya no somos las 'lloronas' que lo único que saben es recordar a Evita los 26 de Julio". ${ }^{67}$ Ahora, señalaba "[h] emos pasado a la ofensiva, organizándonos para la acción junto con nuestros compañeros," siguiendo el ejemplo revolucionario de Eva. Por eso, consideraba que la tarea a realizar era la de:

superar a todos los 'compañeros electoralistas, que dicen creer en elecciones cuando saben que estamos proscriptos. Son hombres con viejas mañas que solamente aparecen cuando hay elecciones y ellos pueden pescar una candidatura, aunque sea de concejal. Entonces se ponen a ofrecer cosas y quieren aparecer como más peronistas que el propio Perón. Pienso que este tipo de gente no nos ha comprendido nunca a nosotros, las bases populares. Todavía se empeñan en formar partidos políticos utilizando nuestra doctrina y nuestro líder, que son esencialmente revolucionarios. Confunden el Movimiento que lucha por terminar para siempre con la injusticia impuesta por unos pocos con un partido al estilo democrático y los radicales, que se turnaron para burlar al pueblo.

Para Romero, las formulaciones neoperonista expresan el oportunismo de ciertos dirigentes que usufructúan los símbolos y el legado peronista para su propio beneficio, en vez de representar las demandas populares. La carencia de representatividad de esas iniciativas frente a las bases, como su comportamiento espurio, ameritaba su expulsión del movimiento, y su

67. Con Evita revolucionaria (21de julio de 1964), Compañero, p. 5. remplazado por conducciones que expresaran reivindicaciones de las masas que deseaban el retorno de Perón y la revolución peronista.

Este conjunto de intervenciones visibiliza diversas demandas femeninas de participación política, poniendo de manifiesto las expectativas de las mujeres ante el proceso de reestructuración partidaria próximo a definirse.

\section{La reorganización peronista}

El examen de Compañero permite analizar las internas del peronismo en relación con el proceso de reorganización partidaria de 1964. Particularmente, la decisión de varios dirigentes -algunos con de peso territorial-, y otros -con llegada directa a Perón- de desconocer la soberanía del cuadriunvirato para reorganizar el peronismo, y gestionar nuevos dispositivos que les permitieran controlar el proceso de reorganización justicialista. ${ }^{68}$ Desde la perspectiva de Valotta, esa actitud desafiante hacia al cuadriunvirato se originaba en las posiciones conciliadoras de ciertos cuadros del movimiento que, debido a su ideología burguesa y, a su "origen de clase", vivían el "desarraigo de la realidad nacional", e intentaban a través "del divisionismo", transformar al peronismo en un partido liberal burgués más. Incluso antes de oficializarse la conformación del cuadriunvira-

68. Por ejemplo, Marcos Anglada desconocía las prerrogativas reorganizativas del cuadrunvirato. Una de las claves su rechazo hacía esta Comisión se encontraba en que se presumía que ésta preferiría la designación "desde arriba" de los funcionarios del Partido (algo que no estaba escrito, pero sí implícito en la designación de un "normalizador" por sección), mientras que los dirigentes cercanos a Anglada propugnaban la elección de los delegados a través del voto directo (Melon Pirro, 2011, pp. 62,63). 
to, el semanario denunciaba una reunión convocaba por Matera en Luján, y de las gestiones de Iturbe para desconocer la potestad del cuadriunvirato para reorganizar el movimiento. ${ }^{69}$

A principios de diciembre de 1963, Compañero informaba sobre la ampliación de la "Comisión Interventora Nacional”, de cuatro a ocho miembros, conocida a partir de entonces como "heptunvirato". ${ }^{70}$ Dicha Comisión, bajo la jefatura de Alberto Iturbe, debía encargarse de conciliar a los diversos sectores que conformaban el heterogéneo movimiento, y controlar formalmente el proceso de normalización justicialista. ${ }^{71}$

La noticia sobre la ampliación del número de miembros de la Comisión Interventora había generado según Compañero "un nivel de decepción que ha cercenado el entusiasmo de

69. Parando la oreja (10 de septiembre de 1963). Compañero, p. 3. Los integrantes del cuadriunvirato preferían la designación "directa y provisional de los funcionarios del partido, mientras que la línea "Las Flores- Lujan”, que reunió a los sectores discordantes, aunaban por la realización de comicios para elegir a las autoridades del peronismo. La presión de éstos últimos desembocó en la convocatoria a elecciones internas a celebrarse el $1^{\circ}$ de diciembre de 1963 con el fin de elegir nuevas autoridades y frenar las iniciativas organizativas que se daban por fuera de la línea oficial del peronismo, y así mediar entre la línea política del movimiento (Anglada), y la sindical (Vandor), en un contexto atravesado por el plan de lucha de la CGT que acrecentaba el capital político de este último. No obstante, lo cual, dichos comicios recién se efectuaron en el mes de julio del año siguiente.

70. Los nuevos integrantes fueron Juana Matti, Miguel Gazzera, Jorge Álvarez, y Carlos Gallo.

71. Melon Pirro (2011) ha planteado que la ampliación del número de miembros se debió a la necesidad de Perón de frenar a distintos referentes de la rama política que, por fuera de la órbita del cuadriunvirato, habían iniciado un proceso tácito de reorganización. las bases". ${ }^{72}$ Desde las páginas del semanario se evaluaba la conformación del heptunvirato como "un retroceso de la línea revolucionaria en el plano político y el avance de "posiciones conciliadoras de la burguesía" que habitaban el movimiento. Su editorialista entendía que "este paso atrás es, en gran parte, producto de la inmadurez de la línea revolucionaria, cuyo desarrollo, sin embargo, es inexorable a pesar de las alternativas circunstanciales" ${ }^{73}$ Es decir, que el cambio en la composición del organismo obedecía a la incapacidad de la conducción revolucionaria para dirigir el proceso de reorganización, que terminaría por convertir al movimiento "en un partido burgués, dirigido a quebrar su potencia revolucionaria y adormecerlo en el falso juego de la 'democracia' parlamentaria".

Compañero se posicionó en abierto enfrentamiento a la línea sostenida por el heptriunvirato. Para el semanario, Solano Lima, Iturbe, Vandor, y las 62 Organizaciones hacían peligrar el alza de la intención revolucionaria que comenzaba a expresarse orgánicamente en los grupos guerrilleros que desarrollan sus actividades en el norte del país, ${ }^{74} \mathrm{y}$ en las acciones realizadas por el MNR Tacuara, ${ }^{75}$ las cuales eran consideradas en la publicación de Valotta como "manifestaciones claras de las condiciones existentes en nuestro país para la lucha

\footnotetext{
72. Arturo, Alberto y Augusto. Tres frigeristas en uno y no se salva ninguno (5 de diciembre de 1963). Compañero, p. 3 .

73. Un paso atrás (5 de diciembre de 1963). Compañero, p. 1.
}

74. Guerrilleros: comienza la lucha en el norte ( $28 \mathrm{de}$ abril de 1964). Compañero, p. 3.

75. Carta abierta a Ezcurra (5 de mayo de 1964).

Compañero, p. 3. 
revolucionaria" ${ }^{76}$ Mientras que la conducción política de la "Comisión Interventora" continuaba en la línea de la institucionalización del movimiento, intentando neutralizar la potencialidad revolucionaria del peronismo. ${ }^{77}$

En ese marco de situación se realizaron las elecciones internas del peronismo el $28 \mathrm{de} \mathrm{ju-}$ nio de 1964 en Capital Federal y en la provincia de Buenos Aires, que finalmente terminaron consagrando a Augusto Vandor como ganador del proceso de normalización. No obstante, los resultados fueron impugnados por sus contrincantes, denunciando el manejo de la organización de los comicios para facilitar el triunfo del vandorismo. De los tres millones de electores con los contaba el peronismo, solo votaron diez mil personas, lo cual quitaba legitimidad a la elección. Pero, además, los comicios terminaron por hacer estallar las rispideces y los disensos acumulados durante el proceso. Miguel Gazzera (fideero) y Jerónimo Izzeta (municipales) -ambos cercanos a las posiciones vandoristas-, rechazaban las impugnaciones del sector de Framini, acusándolo de izquierdista. Estas imputaciones cruzadas desembocaron en la renuncia del líder de la textil a la mesa directiva de las '62 Organizaciones, y su visita a Madrid para denunciar las irregularidades del proceso electoral. ${ }^{78}$

Para Compañero, la ausencia de las masas en los comicios confirmaba la decisión de las bases de no aceptar la "normalización -liberal"

76. Un morto qui parla: vuelve el frentismo. Los burócratas están en el juego (14 de abril de 1964). Compañero, p. 3.

77. Perón no transa: el gobierno y los frentistas 'rebotaron' (21 de abril de 1964). Compañero, p. 3.

78. Aplican los métodos yanquis (4 de agosto de 1964). Compañero, p. 3. que los burócratas buscaban orquestar. En esa coyuntura el seminario informaba que Perón harto de traiciones, "ha decidido volver este año a encabezar la lucha. Porque sabe que aquí las bases, los cuadros medios del movimiento obrero, es decir, del peronismo justamente con los sectores de la JP y todos los demás núcleos revolucionarios del Movimiento, estamos gestando la verdadera organización revolucionaria del peronismo". ${ }^{79}$

Esas percepciones parecieron confirmarse cuando se hizo pública la formación del MRP, y su responsabilidad sobre la conducción del justicialismo local. E1 5 de agosto de 1964, en la sede del sindicato del calzado de la ciudad de Buenos Aires, se celebró su asamblea fundacional. ${ }^{80}$ En la reunión se leyeron documentos donde se explicitaba su carácter federal, ${ }^{81}$ y su programa, legitimado por el mensaje que Villalón, delegado insurreccional de Perón, envío para ser leído en la asamblea. ${ }^{82} \mathrm{~A}$ continuación, se daba a conocer que Compañero, a partir de ese momento, era declarado por el líder exilado como órgano de prensa del movimiento peronista en tanto "expresión actualizada del pensamiento del Gral. Perón." ${ }^{83}$ Este nombramiento, desde hacía tiempo, se expresaba en sus páginas como un anhelo: el de constituir-

79. La farsa de la reorganización: Acto III. Framini Confiesa (4 de agosto de 1964). Compañero, p. 5.

80.5 de agosto, jornada histórica (11 de agosto de 1964). Compañero, p. 1 .

81. MRP: Regreso incondicional de Perón. 'Organizar el ejército popular para la lucha' (11 de agosto de 1964). Compañero, p. 3.

82. MRP El programa y el camino de la revolución (11 de agosto de 1964). Compañero, p. 4.

83. El MRP y Compañero (11 de agosto de 1964).

Compañero, p. 3. 
se en la usina de las proyecciones políticas del movimiento peronista. ${ }^{84}$

Este conclave significó por un breve interregno, el triunfo de la línea revolucionaria que el peronismo debía adoptar para recuperar el poder del Estado frente a las alternativas "frentistas" y "electoralistas" que, de manera contaste y persistente, se denostaban en el semanario. Sin embargo, la algarabía inicial fue acallada veinte días después, cuando a través de una carta, Perón desautorizaba el nuevo nucleamiento político y llamaba a acatar los resultados de las elecciones partidarias celebradas en junio pasado. ${ }^{85}$ Aunque los miembros del MRP terminaran convergiendo en nuevas formaciones políticas vinculadas a la Juventud Revolucionaria Peronista (JRP), Compañero continuó brindando su apoyo a Perón y sosteniendo la predica revolucionaria del peronismo como única opción para su retorno al poder del estado.

\section{Conclusiones}

Tanto 18 de marzo como Compañero intentaron funcionar como la tribuna informativa del peronismo combativo. Desde sus páginas, se

84. Compañero: un año de lucha (9 de junio de 1964). Compañero, p. 1.

85. Melon Pirro (2011) plantea que la decisión de Perón de reconocer el resultado de las elecciones no se debió exclusivamente a la presión de Vandor, sino que, primó por sobre todo, la necesidad del líder exiliado de neutralizar la iniciativa de los senadores Sapag y Ríspoli Roma de crear la "Confederación Nacional de Partidos Justicialistas" que tenía por objeto nuclear las expresiones peronistas provinciales con representación parlamentaria, que finalmente sería contenida por Iturbe. La cercanía de este último con Vandor, y de aquel a su vez, con varios referentes de los peronismos provinciales, impidió una nueva "diáspora" hacía expresiones neoperonistas. expresaron dirigentes sindicales, peronistas de base, representantes de las juventudes y distintos grupos de mujeres quienes pusieron en $\mathrm{pa}-$ labras sus formas de comprender el peronismo y las maneras en que los y las dirigentes del movimiento proscrito debían actuar para recuperar el poder. En ese decir, delinearon marcas de "peronicidad" en relación con la obediencia de la palabra de Perón, pero también de los designios del pueblo, concluyendo que donde estaba el pueblo se encontraba la izquierda, $y$ por ello, el peronismo expresaba acabadamente el sentir popular y revolucionario de sus bases.

Esos argumentos, a su vez, fortalecían las posiciones críticas hacía las conducciones políticas y gremiales que transgredían la voluntad de las bases peronistas que se expresaba en estas publicaciones, pactando con los gobiernos de turno, o con otras fuerzas políticas para convertir al peronismo "en un partido político burgués más" ${ }^{86}$ Desde esta mirada, los desbordes del movimiento peronista difícilmente podían contenerse en los marcos de la institucionalidad burguesa. De allí que estos semanarios apoyaran sustancialmente a aquellos referentes políticos y gremiales que el impulsaran la línea combativa.

La paulatina pérdida de gravitación de ese espacio liderado por Framini en julio de 1964, respecto del ascenso del liderazgo de Vandor, pareció responder a los manejos espurios de este último para vulnerar las decisiones de las bases. Recién en agosto de ese año Compañero pareció lograr la anhelada bendición de $\mathrm{Pe}$ rón como órgano oficial de prensa del movimiento. No obstante, la rápida desautorización del líder exilado al MRP puso de manifiesto

86. Las bases y el plan de lucha. Etchevarne (Metalúrgico). Cumplirlo hasta el fin (18 de febrero de 1964). Compañero, p. 4. 
su preferencia al apoyar la victoria de Vandor en los comicios que poco tiempo atrás había impugnado. A pesar de ello, Valotta continúo apoyando activamente al MRP en los meses siguientes. Una mirada de conjunto a las publicaciones por él alentadas permite advertir las tensiones que habitaron el peronismo durante la primera mitad de la década del ' 60 , a la vez que apreciar la diversidad de actores que encontraron en estos semanarios un espacio para hacer oír su voz sobre los rumbos que el peronismo debía adoptar.

$\propto \tilde{e} \propto$

Recibido: 12-11-2018

Aceptado: 04-04-2019

Publicado: 04-12 -2019 


\section{Referencias bibliográficas}

Bozza, J. A. (2001). El peronismo revolucionario. Itinerario y vertientes de la radicalización, 1959-1969. Sociohistórica, (9,10). Recuperado de http://www.memoria.fahce.unlp.edu.ar/art_revistas/pr.2942/ pr.2942.pdf

Caruso, V., Campos, E., Vigo, M., Acha, A. (2017). Izquierda peronista: una categoría útil para el análisis histórico, Historiografías, (14), 68-90. https://doi.org/10.26754/ojs_historiografias/hrht.2017142337

Caruso, V. (2019). Intelectuales e izquierda peronista: sus relaciones con la universidad y el movimiento obrero (1955-1973) (Tesis doctoral inédita). Universidad de Buenos Aires, Buenos Aires, Argentina.

Garzón Rogé, M. (2017). Un espécimen peronista. Pruebas de identidad y modos prácticos de ser en el primer peronismo. Pilquen, 21(4), 82-95. Recuperado de http://revele.uncoma.edu.ar/htdoc/revele/index. $\mathrm{php} /$ Sociales/article/view/1792/1829

Mathias, C. (2017). Populismo en espera. Después del partido y antes del partido: el Consejo Coordinador y Supervisor del peronismo. En J. Chiaramonte, y H. Klein (Coords.), El exilio de Perón. Los papeles del Archivo Hoover. Buenos Aires: Sudamericana.

Marcilese, J. (2014). De la proscripción a la participación, el peronismo bonaerense entre el Partido Justicialista y la Unión Popular (1959-1962), Sociohistórica, (33). Recuperado de http:/www.sociohistorica. fahce.unlp.edu.ar/article/view/SH2014n33a05.

Melon Pirro, J. (2007). Informe sobre la prensa clandestina. Los peronistas entre 1955 y 1960. En L. Da Orden y J. Melon Pirro (Comps.), Prensa y peronismo. Discursos, prácticas y empresas, 1943-1958. Rosario: Prohistoria.

Melon Pirro, J. (2011). Un partido en situación de espera. Los alineamientos políticos del peronismo en el segundo momento de la proscripción, 1963-1964. En L. Da Orden y J. Melon Pirro (Comps.), Organización política y Estado en tiempos del peronismo (pp. 61-74). Rosario: Prohistoria.

Rodney, N. (1975). Polythetic Classification: Convergence and Consequences. Man, (10), 349-369.

Raimundo, M. (2001). Compañero y los orígenes del Peronismo Revolucionario. Sociobistórica, (8), 203-226. Recuperado de http://www.memoria.fahce.unlp.edu.ar/art_revistas/pr.2897/pr.2897.pdf

Smulovitz, C. (1988), Crónica de un final anunciado: las elecciones de marzo de 1962 Desarrollo Económico, 28(109), 105-119.

Tortti, M. C. (2010). Soluciones: una experiencia de acercamiento entre el peronismo y la izquierda durante la campaña por el voto en blanco en 1960. Ponencia presentada en el II Congreso de Estudios sobre el Peronismo (1943-1976), Buenos Aires, Argentina.

Tortti, M. C. (2014). Che. Una Revista De La Nueva Izquierda (1960-1961). Buenos Aires: CeDInCI. 